\title{
Association between increasing agricultural use of 2,4-D and population biomarkers of exposure: findings from the National Health and Nutrition Examination Survey, 2001-2014
}

Marlaina S. Freisthler ${ }^{1}$, C. Rebecca Robbins ${ }^{1}$, Charles M. Benbrook ${ }^{2}$, Heather A. Young ${ }^{1}$, David M. Haas ${ }^{3}$, Paul D. Winchester ${ }^{4}$ and Melissa J. Perry ${ }^{1 *}$ (1)

\begin{abstract}
Background: 2,4-Dichlorophenoxyacetic acid (2,4-D) is one of the most extensively used herbicides in the United States. In 2012, 2,4-D was the most widely used herbicide in non-agricultural settings and the fifth most heavily applied pesticide in the US agricultural sector. The objective of this study was to examine trends in 2,4-D urinary biomarker concentrations to determine whether increases in 2,4-D application in agriculture are associated with increases in biomonitoring levels of urine 2,4-D.
\end{abstract}

Methods: Data from the National Health and Nutrition Examination Survey (NHANES) with available urine 2,4-D biomarker measurements from survey cycles between 2001 and 2014 were utilized. Urine 2,4-D values were dichotomized using the highest limit of detection (LOD) across all cycles $(0.40 \mu \mathrm{g} / \mathrm{L}$ or $0.4 \mathrm{ppb})$. Agricultural use of 2,4-D was estimated by compiling publicly available federal and private pesticide application data. Logistic regression models adjusted for confounders were fitted to evaluate the association between agricultural use of 2,4-D and urine 2,4-D level above the dichotomization threshold.

Results: Of the 14,395 participants included in the study, 4681 (32.5\%) had urine 2,4-D levels above the dichotomization threshold. The frequency of participants with high 2,4-D levels increased significantly $(p<.0001)$, from a low of 17.1\% in 2001-2002 to a high of 39.6\% in 2011-2012. The adjusted odds of high urinary 2,4-D concentrations associated with 2,4-D agricultural use (per ten million pounds applied) was 2.268 (95\% Cl: 1.709, 3.009). Children ages 6-11 years $(n=2288)$ had 2.1 times higher odds of having high 2,4-D urinary concentrations compared to participants aged 20-59years. Women of childbearing age (age 20-44years) $(n=2172)$ had 1.85 times higher odds than men of the same age.

Conclusions: Agricultural use of 2,4-D has increased substantially from a low point in 2002 and it is predicted to increase further in the coming decade. Because increasing use is likely to increase population level exposures, the associations seen here between 2,4-D crop application and biomonitoring levels require focused biomonitoring and epidemiological evaluation to determine the extent to which rising use and exposures cause adverse health

\footnotetext{
*Correspondence: mperry@gwu.edu

1 Department of Environmental and Occupational Health, Milken Institute

School of Public Health, The George Washington University, 950 New

Hampshire Ave NW Suite 400, Washington, DC 20052, USA

Full list of author information is available at the end of the article
} permits use, sharing, adaptation, distribution and reproduction in any medium or format, as long as you give appropriate credit to the original author(s) and the source, provide a link to the Creative Commons licence, and indicate if changes were made. The images or other third party material in this article are included in the article's Creative Commons licence, unless indicated otherwise in a credit line to the material. If material is not included in the article's Creative Commons licence and your intended use is not permitted by statutory regulation or exceeds the permitted use, you will need to obtain permission directly from the copyright holder. To view a copy of this licence, visit http://creativecommons.org/licenses/by/4.0/. The Creative Commons Public Domain Dedication waiver (http://creativeco mmons.org/publicdomain/zero/1.0/) applies to the data made available in this article, unless otherwise stated in a credit line to the data. 
outcomes among vulnerable populations (particularly children and women of childbearing age) and highly exposed individuals (farmers, other herbicide applicators, and their families).

Keywords: Environmental epidemiology, Environmental exposure, Pesticides

\section{Introduction}

2,4-Dichlorophenoxyacetic acid (2,4-D) is one of the most extensively used herbicides in the United States. Roughly 600 US agricultural and residential use products contain 2,4-D as the active ingredient [1, 2]. In 2012, 2,4-D was the most widely used herbicide in home and garden settings, roughly equal to glyphosate in use in the combined non-agricultural settings, and the fifth most heavily applied pesticide in the US agricultural sector [3].

2,4-D is rapidly absorbed via oral and inhalation routes [4]. In prior evaluations in the Agricultural Health Study (AHS), 71\% of 2,4-D applicators from Minnesota and South Carolina had 2,4-D in their urine prior to applying it to their crops, while $100 \%$ had it in their urine postapplication [5]. AHS research has also reported that $41 \%$ of spouses and $62 \%$ of children of the agricultural workers had detectable levels of 2,4-D in their urine pre-application [6]. Farm family members are typically exposed to pesticides via multiple routes, including food, drinking water, inhalation and dermal exposure following spray drift or movement of volatile compounds [7]. Those who live near areas of heavy agricultural 2,4-D use often have increased exposure from dermal contact, inhalation of soil particles, and contact with people, clothing, or pets that have been exposed [1].

Non-occupational exposure studies have reported that farm families are not the only population at risk of 2,4-D exposure. Exposure to 2,4-D also occurs via food, water, dust, dirt, and pet exposure in non-agricultural households. An evaluation of exposure in children and their adult caregivers outside of the agricultural context found that 2,4-D was detected in 83 and 98\% of household carpet dust samples in six counties each in North Carolina and Ohio, respectively, as well as in more than $85 \%$ of participants' spot urine samples in both locations [8]. The general population is exposed to 2,4-D through ingestion of food and water containing residues of 2,4-D [1], as well as through ambient non-occupational residential exposures, particularly in areas where 2,4-D has been widely used in controlling weeds in lawns and urban spaces [9]. The toxicological profile for 2,4-D indicates that it is highly mobile in soil and has the potential to migrate into groundwater [1], a particular concern for households near high-application areas.

US agricultural application patterns of 2,4-D use over time are showing major increases, particularly since the shift towards weed management through reliance on genetically modified herbicide resistant seeds in the early 2000 s triggered the emergence and spread of glyphosateresistant weeds $[2,10,11]$; however, how these increases are affecting human exposure is not known. As increasing rates of exposure are anticipated due to the planting of herbicide-resistant seeds in conjunction with the wider, more frequent use of multi-ingredient herbicide premixes, innovative biomarker analyses are becoming increasingly essential in evaluating human health impacts. The objective of this study was to examine trends in 2,4-D urinary biomarker concentrations in a nationally representative US population from 2001 to 2014 to determine whether increases in 2,4-D application in agriculture are associated with increases in biomonitoring levels of urine 2,4-D as a measure of population exposure, and to identify any population subgroups who are more likely to be exposed.

\section{Methods}

\section{Biomonitoring data}

The National Health and Nutrition Examination Survey (NHANES) is a continuous, nationally representative, cross-sectional survey of the non-institutionalized civilian US population. It is conducted by the U.S. Centers for Disease Control and Prevention (CDC) and published in two-year waves. Urine 2,4-D has been measured as part of a randomly selected environmental exposure subsample, typically representing around one-third of the overall sample [12]. Spot urine samples collected during scheduled appointments at a mobile examination center were immediately aliquoted and stored at -20 degrees Celsius prior to shipping for analysis at CDC's National Center for Environmental Health in Atlanta, Georgia [13].

Although inhalation and dermal routes are important exposure sources in occupational settings, non-occupational 2,4-D exposures in humans are presumed to happen primarily through ingestion [14, 15]. Most of the 2,4-D consumed orally is absorbed in the gastrointestinal tract [15]. Because it is minimally metabolized prior to urinary excretion [1] and retains its parent form in urine, no other associated analytes/metabolites are analyzed to evaluate exposure. An automated solid phase extraction system was used to extract and concentrate 2,4-D from the urine matrix. High-performance liquid chromatography with gradient elution was used to selectively separate 2,4-D, which was then detected, identified, and quantified 
by a triple quadrupole mass spectrometer with a heated electrospray ionization source [16].

All 2,4-D data files were downloaded from the NHANES website in June 2020. All survey cycles in which 2,4-D biomonitoring data were available except the 1999-2000 cycle were utilized for this analysis. The 1999-2000 cycle was excluded because the 2,4-D limit of detection (LOD) was more than two times higher than the LOD of subsequent surveys $(1.0 \mu \mathrm{g} / \mathrm{L}$ or $1 \mathrm{ppb})$. Because the 2005-2006 surveys and all surveys after the 2013-2014 cycle did not include 2,4-D biomarkers, they were not included in this analysis. The survey cycles utilized were the 2001-02, 2003-04, 2007-08, 2009-10, 2011-12, and 2013-14cycles. Across these six cycles, a total of 61,778 participants were surveyed with 16,553 participants in the environmental exposure subsample. Urine 2,4-D measurements were available from 15,761 (95.2\%) participants. Participants were excluded who had data missing on household income $(n=1199)$, educational background $(n=20)$, status as an agricultural worker $(n=22)$, or spot urine creatinine level $(n=8)$, resulting in a total of $14,395(90.3 \%)$ participants included in this study.

Limits of detection (LOD) for urine 2,4-D metabolites varied by cycle from $0.15-0.40 \mu \mathrm{g} / \mathrm{L}$, with 5907 samples (41.04\%) falling below the respective LOD. Due to the variability of the LODs and the high percentage of results falling below the LOD, urine 2,4-D values were dichotomized using the highest LOD level across all cycles $(0.40$ $\mu \mathrm{g} / \mathrm{L}$ or $0.4 \mathrm{ppb})$. Approximately one third (32.52\%) of detections fell above the dichotomization threshold and were considered the high exposure group, while the remaining two thirds falling below the dichotomization threshold were considered the low/no exposure group. High compared to low urinary concentrations was the main outcome of interest because, while low exposures may pose health risks, higher 2,4-D exposures have been associated with negative health outcomes in prior studies.

\section{Covariates}

In the NHANES survey, participants were asked about the industry in which they were employed and their occupation. Both were coded according to the US Census Bureau's Industry and Occupation Codes [17]. For this study, a participant was considered an agricultural worker if they reported agricultural sector for either their industry or occupation. Children under age 16 were presumed not to be agricultural workers because they do not participate in the NHANES Occupation Questionnaire.

Adults were considered to be smokers if their cotinine levels on laboratory analysis were greater than $10 \mathrm{ng} /$ $\mathrm{mL}$, or if they self-reported as smokers [18]. They were considered non-smokers if their cotinine levels were less than or equal to $10 \mathrm{ng} / \mathrm{mL}$. If a laboratory value was not available, participants were considered to be non-smokers if they self-reported as a non-smoker. Children under age 12 were not questioned regarding their smoking status and were considered to be non-smokers unless their cotinine value was greater than $10 \mathrm{ng} / \mathrm{mL}$ on laboratory analysis [18].

\section{Pesticide use data}

The amount of 2,4-D applied annually was estimated for specific crops using the United States Department of Agriculture (USDA) National Agricultural Statistics Service (NASS) survey data (see Fig. 1 and Additional file 1) using methods described previously [19]. Briefly, since 1990, NASS has reported annually pesticide applications at the national and state level for most major field crops. Fruit crops are surveyed in even years and vegetable crops in odd years. Although the NASS surveys a limited number of crops in any given year and no crop every year, use data is commonly interpolated for years in which data are not available based on the assumption of equal percentage changes year-to-year between two years with reported values. Additional but less granular pesticide use data are available in periodic U.S. Environmental Protection Agency (EPA) reports. These reports provide the most complete estimates of total use in both agriculture and non-agricultural settings; the most recent report in this EPA series provides data through 2012 [3]. Detailed proprietary data are issued annually by private companies and are used by the EPA to augment the results from annual USDA surveys. Another dataset is compiled and shared publicly by the United States Geological Service.

Results from NASS and EPA were compiled in the Pesticide Use Data System (PUDS) [19] to produce annual data from 1974 through 2020 on 2,4-D use in agriculture. Annual USDA surveys report use data for multiple forms of 2,4-D. In PUDS, conglomerate values for a given pesticide integrate multiple forms of an active ingredients into a single set of data (see Additional file 2). To examine exposure biomarkers in relation to per-year pesticide use, the average amount of aggregate 2,4-D applied per year within an NHANES cycle was determined by summing the amount of 2,4-D applied in each of the two years and then dividing by two.

\section{Statistical analysis}

NHANES oversamples some minority demographics (e.g., race/ethnicity and older age) in order to better identify health trends and then applies sample weights to ensure that the sample is nationally representative [20]. It also uses clustering in its sampling strategy, to account for non-random community and family relationships 


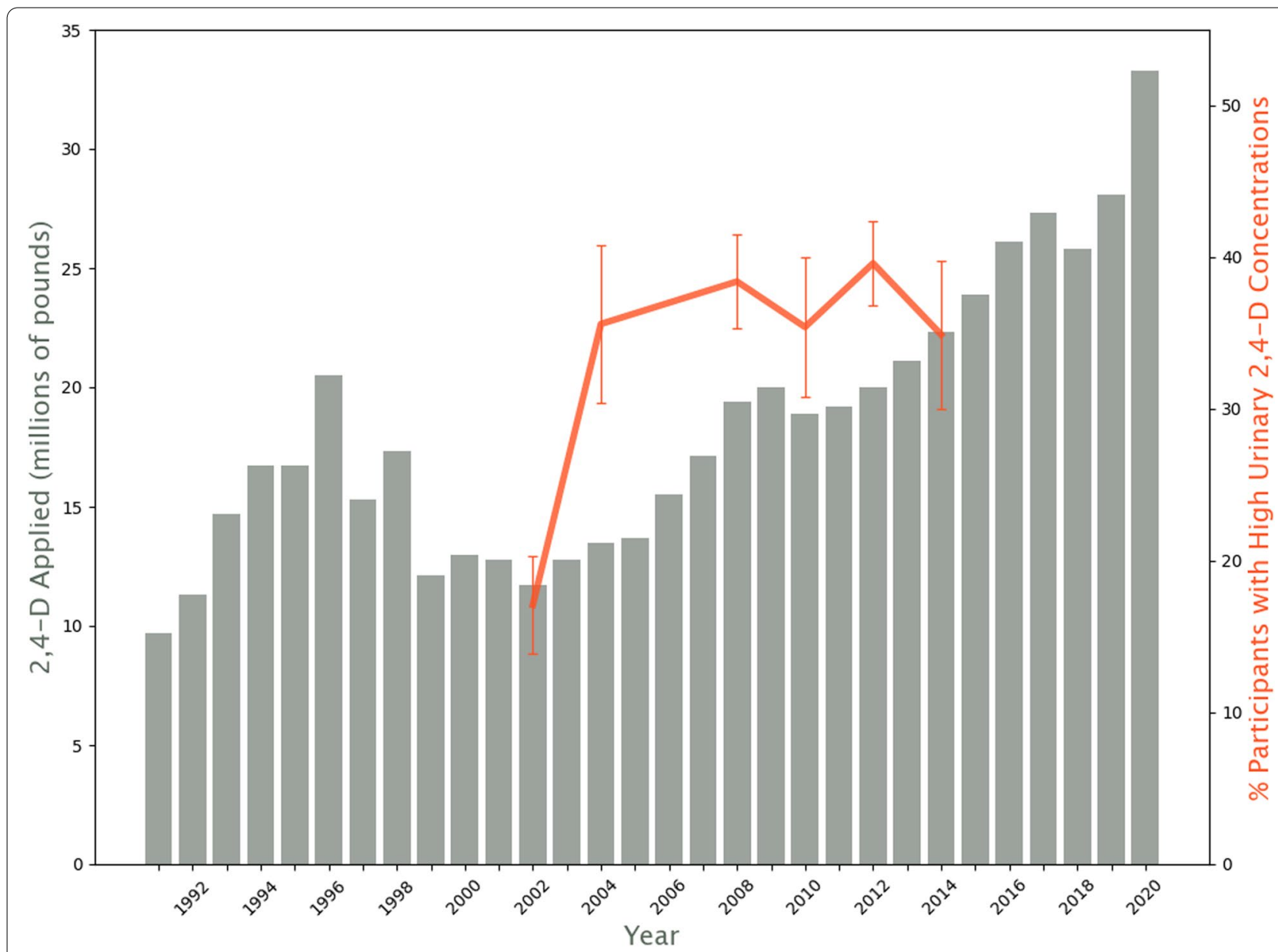

Fig. 1 2,4-D Agricultural Use and NHANES Urinary Concentrations Over Time. Legend: Estimated agricultural use of 2,4-D per year in

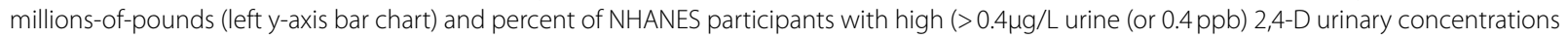
(right y-axis line chart, with 95\% confidence interval bars) by concluding year of NHANES survey

among survey participants [20]. To account for these factors, analyses were performed using survey procedures to adjust for nonrandom sampling design and sample population weights [20].

Sample weights and degrees of freedom were calculated according to the NHANES analytic guidelines [21]. Separate sampling weights are provided for each NHANES cycle. Because each sample weight represents only one cycle, and six cycles were analyzed, sampling weights for this analysis were calculated by assigning a value of one-sixth of the two-year subsample weights, in accordance with recommended procedures [21]. Degrees of freedom were calculated as the number of clusters in the second level of sampling (primary sampling units) minus the number of clusters in the first sampling unit (strata) [21]. With 94 degrees of freedom, a critical value of \pm 1.986 was derived from the $t$-distribution for the calculation of confidence intervals in all inferential analyses. Taylor series linearization was used to compute variance estimates [22]. Analyses were conducted in SAS version 9.4 (SAS Institute, Cary, NC).

Multivariable logistic regression models were used to assess the relationship between urinary 2,4-D concentrations and the average amount of 2,4-D used in crop applications per year across the survey cycle (in tenmillion-pound units), adjusting for potential covariates. Based on a priori assumptions from prior research on pesticide biomarkers, age, sex (male versus female), family poverty to income ratio, race (non-Hispanic Black, Mexican American, and Other Race/Ethnicity versus non-Hispanic White), and agricultural worker status (yes/no) were included as covariates. All regression models controlled for creatinine level to account for urinary dilution, which can affect accuracy in urinary pesticide detections [23]. Smoking status, education level (Grade 8 or less, Grades 9-12, and high school graduate versus some college) and season of testing (May 1-October 31 vs. November 1-April 30) were evaluated as potential 
confounders and were retained if their inclusion significantly changed $(>10 \%)$ the odds ratio of the main association in any model. Additional multivariable analyses for target age group and sex were performed using similar modelling techniques to evaluate associations in high-risk subgroups. These subgroups were identified

Table 1 Participant Characteristics and Distribution of Higher Urine 2,4-D Concentrations. Legend: Distribution of high (>0.4 $\mu \mathrm{g} / \mathrm{L}$ urine) 2,4-D urinary concentrations and associations with key variables in unadjusted models. * $=$ reference level

\begin{tabular}{|c|c|c|c|c|c|c|}
\hline Variable & $\begin{array}{l}\text { Frequency } \\
\text { (\%) }\end{array}$ & $\begin{array}{l}\text { Population } \\
\text { Estimate }\end{array}$ & $\begin{array}{l}\text { High Urine } \\
2,4-D \\
\text { in Sample }\end{array}$ & $\begin{array}{l}\text { Estimated Population } \\
\text { with High Exposure }\end{array}$ & $\begin{array}{l}\text { \% with } \\
\text { High 2,4-D } \\
(95 \% \mathrm{Cl})\end{array}$ & $\begin{array}{l}\text { Unadjusted } \\
\text { Odds Ratio } \\
(95 \% \mathrm{Cl})\end{array}$ \\
\hline Total & 14,395 & $244,607,215$ & 4681 & $82,642,980$ & $33.8(32.1,35.5)$ & \\
\hline \multicolumn{7}{|l|}{ Survey Cycle } \\
\hline 2001-2002 & $2685(15.1)$ & $37,004,806$ & 457 & $6,332,340$ & $17.1(13.9,20.3)$ & ref \\
\hline 2003-2004 & $2347(16.4)$ & $40,112,380$ & 855 & $14,269,430$ & $35.6(30.4,40.8)$ & $2.67(1.99,3.70)$ \\
\hline $2007-2008$ & $2311(16.4)$ & $40,153,846$ & 898 & $15,427,421$ & $38.4(35.3,41.5)$ & $3.02(2.32,3.94)$ \\
\hline 2009-2010 & $2450(16.9)$ & $41,228,734$ & 823 & $14,582,297$ & $35.4(30.8,40.0)$ & $2.65(1.95,3.61)$ \\
\hline 2011-2012 & $2146(17.3)$ & $42,213,815$ & 791 & $16,716,965$ & $39.6(36.8,42.4)$ & $3.17(2.45,4.11)$ \\
\hline 2013-2014 & $2456(17.9)$ & $43,893,633$ & 857 & $15,314,527$ & $34.9(30.0,39.8)$ & $2.60(1.89,3.56)$ \\
\hline \multicolumn{7}{|l|}{ Sex } \\
\hline Male & 7099 (49.0) & $119,753,832$ & 2614 & $46,199,838$ & $38.6(36.5,40.7)$ & $1.521(1.39,1.67)$ \\
\hline Female & $7296(51.0)$ & $124,853,382$ & 2067 & $36,443,142$ & $29.2(27.3,31.1)$ & ref \\
\hline \multicolumn{7}{|l|}{ Race/Ethnicity } \\
\hline Non-Hispanic White & $5922(67.1)$ & $164,017,859$ & 2068 & $58,251,760$ & $35.5(33.3,37.7)$ & ref \\
\hline Non-Hispanic Black & $3313(11.7)$ & $28,583,574$ & 1046 & 601,943 & $31.3(28.8,33.8)$ & $0.83(0.72,0.95)$ \\
\hline Mexican American & $2850(9.0)$ & $21,996,531$ & 887 & $7,054,921$ & $32.1(29.0,35.2)$ & $0.86(0.73,1.01)$ \\
\hline Other & $2310(12.3)$ & $30,009,251$ & 680 & $8,389,887$ & $28.0(25.1,30.9)$ & $0.70(0.60,0.83)$ \\
\hline \multicolumn{7}{|l|}{ Age (years) } \\
\hline $6-11$ & $2288(9.2)$ & $22,586,413$ & 874 & $9,571,185$ & $42.4(38.8,46.0)$ & $1.60(1.40,1.83)$ \\
\hline $12-19$ & $2846(12.1)$ & $29,636,700$ & 914 & $10,290,245$ & $34.7(31.5,37.9)$ & $1.16(1.01,1.33)$ \\
\hline $20-59$ & $6243(60.0)$ & $146,678,123$ & 1875 & $46,214,496$ & $31.5(29.7,33.3)$ & ref \\
\hline $60+$ & 3018 (18.7) & $45,705,978$ & 1018 & $16,567,054$ & $36.2(33.7,38.7)$ & $1.24(1.11,1.37)$ \\
\hline \multicolumn{7}{|l|}{ Education } \\
\hline Grade 8 or Less & 4569 (18.9) & $46,298,948$ & 1585 & $17,680,657$ & $38.2(35.5,40.9)$ & $1.34(1.16,1.55)$ \\
\hline Grade 9-12 & $2615(14.4)$ & $35,342,844$ & 799 & $10,865,543$ & $30.7(28.4,33.0)$ & $0.96(0.84,1.11)$ \\
\hline High School Graduate & $2272(18.3)$ & $44,797,645$ & 676 & $14,125,909$ & $31.5(28.5,34.5)$ & ref \\
\hline Any College & $4939(48.3)$ & $118,167,779$ & 1621 & $39,970,871$ & $33.8(31.8,35.8)$ & $1.11(0.97,1.27)$ \\
\hline \multicolumn{7}{|l|}{ Poverty Income Ratio } \\
\hline Up to $100 \%$ & 3638 (16.6) & $40,513,665$ & 1082 & $12,330,209$ & $30.4(28.3,32.5)$ & $0.79(0.71,0.89)$ \\
\hline $100-200 \%$ & 3898 (21.5) & $52,546,663$ & 1228 & $16,365,202$ & $31.1(28.8,33.4)$ & $0.82(0.73,0.91)$ \\
\hline Over 200\% & $6859(62.0)$ & $151,546,887$ & 2371 & $53,947,570$ & $35.6(33.6,37.6)$ & ref \\
\hline \multicolumn{7}{|l|}{ Agricultural Worker } \\
\hline No & $14,256(98.9)$ & $242,014,960$ & 4620 & $81,271,238$ & $33.6(31.9,35.3)$ & ref \\
\hline Yes & $139(1.1)$ & $2,592,255$ & 61 & $1,371,742$ & $52.9(46.3,59.5)$ & $2.23(1.33,3.73)$ \\
\hline \multicolumn{7}{|l|}{ Smoking Status } \\
\hline No & $11,444(76.3)$ & $186,588,955$ & 3869 & $66,274,113$ & $35.5(33.7,37.3)$ & ref \\
\hline Yes & $2951(23.7)$ & $58,018,260$ & 812 & $16,368,867$ & $28.2(25.6,30.8)$ & $0.71(0.63,0.81)$ \\
\hline \multicolumn{7}{|l|}{ Season } \\
\hline May 1-October 31 & $7469(59.0)$ & $100,371,111$ & 2446 & $50,441,699$ & $35.0(32.5,37.5)$ & $1.14(0.97,1.33)$ \\
\hline November 1-April 30 & $6926(41.0)$ & $144,236,103$ & 2235 & $32,201,281$ & $32.1(30.9,33.3)$ & ref \\
\hline \multicolumn{7}{|l|}{ Water Source } \\
\hline Water Company & 8646 (84.6) & $132,271,816$ & 2669 & $42,110,899$ & $31.8(29.6,34.0)$ & $1.04(0.87,1.24)$ \\
\hline Well & $1020(15.4)$ & $24,127,699$ & 315 & $7,487,755$ & $31.0(27.3,34.7)$ & ref \\
\hline
\end{tabular}


a priori because of interest in exposure levels relative to developmental and reproductive vulnerability [24]. Specifically, models were fitted for age groups 6-11 years, $12-19$ years, $20-59$ years, and $60+$ years, and separately for men and women of childbearing age (20-44years). The same covariates were initially evaluated for all models. A two-sided $p$-value $<0.05$ was considered statistically significant.

\section{Results}

Descriptive statistics for the total sample are detailed in Table 1 . Of the 14,395 participants included in the study, $4681(32.5 \%)$ had urine 2,4-D levels above $0.40 \mu \mathrm{g} / \mathrm{L}$ or $0.4 \mathrm{ppb}$. Table 1 contains unadjusted odds ratios of higher urinary 2,4-D concentration by predictor variables. Many of the unadjusted demographic analyses showed significant associations with high 2,4-D concentrations including by gender, race, and poverty level. Men had a higher odds of high 2,4-D urinary concentrations compared to women (OR: 1.52, 95\% CI: 1.39, 1.67). Non-Hispanic White participants had higher odds of high urinary 2,4-D concentrations compared to Non-Hispanic Black participants (OR: 0.83, 95\% CI: 0.72, 0.95), Mexican American participants (OR: $0.86,95 \%$ CI $0.73,1.01$ ), and participants of other races/ethnicities (OR: 0.70, 95\% CI: 0.60, 0.83). Participants with an income over $200 \%$ of the poverty level had higher odds compared to participants with income levels $100-200 \%$ of poverty level (OR: 0.82 , $95 \%$ CI: $0.73,0.91$ ) and up to $100 \%$ of the poverty level (OR: 0.79, 95\% CI: 0.71, 0.89). Participants who worked in the agricultural sector had higher odds than those who did not (OR: 2.23, 95\% CI: 1.33, 3.73), and those who did not smoke had higher odds than those who did (OR: 0.71, 95\% CI: $0.63,0.81$ ). By age, compared to participants aged $20-59$, the odds were higher for children aged $6-11$ years (OR: $1.60,95 \% \mathrm{CI}: 1.40,1.83$ ) and $12-19$ years (OR: 1.16, 95\% CI: 1.01, 1.33), as well as for participants aged 60 years or older (OR: 1.24, 95\% CI: 1.11, 1.37).

As detailed in Fig. 1, the percent of participants with high 2,4-D urinary concentrations increased significantly over the series of surveys $(p<.0001)$, from a low of $17.1 \%$ in the 2001-2002 survey to a high of $39.6 \%$ in the $2011-$ 2012 survey.

Results of bivariate and multivariable logistic regression analyses for all participants and for each age and sex group of interest are reported in Table 2. In the full sample, the unadjusted odds ratio for high urinary 2,4-D concentration associated with pounds of 2,4-D utilized in crop applications (per ten-million-pound unit) was 1.85 (95\% CI: $1.44,2.38, p<.0001)$. In the adjusted models, all covariates selected a priori (age, sex, poverty ratio, race/ ethnicity, and agricultural worker status) were retained.

Table 2 Adjusted and Unadjusted Associations Between Agricultural Application of 2,4-D and NHANES Urine 2,4-D Concentrations. Legend: Unadjusted and adjusted odds of high 2,4-D urinary concentrations by agricultural use of 2,4-D, age, gender, and other key variables for NHANES participants 2001-2014

\begin{tabular}{|c|c|c|c|c|c|c|c|}
\hline \multirow[t]{2}{*}{ Variable } & All Participants & Age 6-11 & Age $12-20$ & Age 20-59 & Age 60+ & $\begin{array}{l}\text { Female, } \\
\text { Age 20-44 }\end{array}$ & $\begin{array}{l}\text { Male, } \\
\text { Age 20-44 }\end{array}$ \\
\hline & $n=14,395$ & $n=2288$ & $n=2846$ & $n=6243$ & $n=3018$ & $n=2172$ & $n=1932$ \\
\hline \multicolumn{8}{|l|}{ Unadjusted OR (95\% CI) } \\
\hline $\begin{array}{l}\text { Agricultural } \\
\text { 2,4-D Applied }\end{array}$ & $1.85(1.44,2.38)$ & $3.41(2.18,5.34)$ & $1.77(1.20,2.60)$ & $2.54(1.18,2.01)$ & $2.47(1.82,3.36)$ & $2.29(1.54,3.40)$ & $1.24(0.85,1.80)$ \\
\hline \multicolumn{8}{|l|}{ Adjusted OR (95\% Cl) } \\
\hline $\begin{array}{l}\text { Agricultural } \\
\text { 2,4-D Applied }\end{array}$ & $2.27(1.71,3.01)$ & $4.24(2.52,7.13)$ & $2.38(1.54,3.68)$ & $1.99(1.45,2.73)$ & $2.70(1.87,3.91)$ & $2.87(1.82,4.53)$ & $1.55(1.02,2.36)$ \\
\hline Age & $1.00(1.00,1.01)$ & $0.87(0.81,0.94)$ & $0.93(0.88,0.99)$ & $1.02(1.01,1.03)$ & $1.02(1.01,1.04)$ & $1.01(0.99-1.04)$ & $1.01(1.00-1.03)$ \\
\hline Gender ${ }^{b}$ & $0.87(0.79,0.97)$ & $0.94(0.74,1.18)$ & $0.78(0.62,0.99)$ & $0.94(0.81,1.10)$ & $0.88(0.68,1.14)$ & - & - \\
\hline \multicolumn{8}{|l|}{ Race/Ethnicity } \\
\hline Non-Hispanic White & ref & ref & ref & ref & ref & ref & ref \\
\hline Mexican American & $0.83(0.68,1.02)$ & $0.68(0.49,0.96)$ & $0.87(0.63,1.18)$ & $0.90(0.69,1.18)$ & $0.75(0.53,1.07)$ & $1.00(0.66-1.51)$ & $0.76(0.54-1.07)$ \\
\hline Non-Hispanic Black & $0.57(0.48,0.66)$ & $0.47(0.34,0.64)$ & $0.68(0.49,0.94)$ & $0.52(0.42,0.65)$ & $0.58(0.45,0.75)$ & $0.53(0.38-0.75)$ & $0.45(0.33-0.62)$ \\
\hline Other & $0.69(0.57,0.82)$ & $0.50(0.35,0.72)$ & $0.77(0.56,1.08)$ & $0.73(0.56,0.94)$ & $0.71(0.49,1.04)$ & $0.63(0.43-0.93)$ & $0.69(0.49-0.98)$ \\
\hline Poverty Income Ratio & $1.06(1.02,1.10)$ & $1.12(1.04,1.23)$ & $1.06(0.97,1.16)$ & $1.06(1.00,1.11)$ & $1.09(1.01,1.17)$ & $1.08(0.98-1.18)$ & $1.01(0.94-1.08)$ \\
\hline Urine Creatinine (mg/dL) & $1.01(1.01,1.01)$ & $1.02(1.01,1.02)$ & $1.01(1.01,1.01)$ & $1.01(1.01,1.01)$ & $1.01(1.01,1.01)$ & $1.01(1.01-1.01)$ & $1.01(1.01-1.01)$ \\
\hline Agricultural Worker & $2.11(1.33,3.36)$ & - & $1.81(0.64,5.13)$ & $2.64(1.41,4.94)$ & $2.34(0.59,9.25)$ & $2.26(0.54-9.42)$ & $2.85(1.42-5.69)$ \\
\hline
\end{tabular}


Education, smoking, and season of testing were not retained as covariates due to lack of change in effect.

The overall adjusted odds ratio for pounds of 2,4-D applied was 2.27 (95\% CI: 1.71, 3.01, p<.0001). In adjusted models, agricultural work was a significant predictor of higher urinary 2,4-D concentrations overall, as well as for adults aged $20-59$ and men aged $20-44$. Several of the models showed an increased odds of higher exposure in specific age and sex groups. Children ages $6-11$ years $(n=2288)$ had 2.1 times higher odds of having higher urinary 2,4-D concentrations compared to participants aged 20-59years, while participants aged 60 years and older $(n=3018)$ had 1.36 times higher odds. Within the 6-11- and 12-19-years age ranges, age was a significant predictor, indicating that among children within each age group, younger children had higher odds of higher exposure than older children. Women of childbearing age (age 20-44 years) $(n=2172)$ had odds 1.85 times higher than men of the same age.

\section{Discussion}

This study evaluated the relationship between crop application of 2,4-D and urine biomarkers of exposure in a large, nationally representative sample of 14,395 participants. There were significant associations between crop application of 2,4-D and the percent of NHANES participants with high 2,4-D urinary concentrations (adjusted odds ratio 2.27 (95\% CI: 1.71, 3.01, $p<.0001$ )). This study demonstrates that as average annual use of 2,4-D increased, individuals had increased odds of having higher urinary 2,4-D concentrations.

Overall, the amount of 2,4-D applied in agriculture has risen nearly $67 \%$ between 2012 and 2020, and over $240 \%$ between 1991 and 2020 (see Additional file 1), a trend that is unlikely to change due to unabated weed resistance. 2,4-D use began in 1945 and dramatically increased over the next two decades. In the late 1960's, reliance on 2,4-D declined due to the emergence of other selective herbicides such as atrazine, although it remained the herbicide of choice for most wheat growers [2, 10,11]. Commercial sale of genetically engineered glyphosate-tolerant "Roundup ${ }^{\text {TM }}$ Ready" soybeans and cotton began in 1996. Cost-effectiveness and simplicity of use led to rapid and widespread adoption of the Roundup ${ }^{\mathrm{TM}}$ system (see Additional files 3 and 4), causing sales of 2,4-D and all other herbicides to decline sharply in these three crops (see Additional files 5 and 6). By the mid 2000s, three hardto-control weeds had developed resistance to glyphosate in the southeastern US and were spreading rapidly north and west from farm to farm and across state lines. The problem worsened from a few resistant weeds in scattered fields to economically damaging resistant weed populations in many fields by the mid 2010s [25, 26].
The growing diversity and spread of resistant weeds have forced farmers to add additional herbicides, often including 2,4-D, to their weed control programs [25].

In response to increasing herbicide resistance in weeds, the pesticide industry developed DuoEnlist ${ }^{\mathrm{TM}}$ technology, which EPA approved in 2017. This technology couples seeds genetically engineered to tolerate 2,4-D, glyphosate, and 4-Hydroxyphenylpyruvate dioxygenase inhibitors (HPPD inhibitors, aka "fop" herbicides) with new formulations of glyphosate and 2,4-D designed to reduce volatility, drift, and off-target crop damage. Reliance on the DuoEnlist ${ }^{\text {TM }}$ system has caused the use of 2,4-D to rise sharply in both soybean and cotton production, with further increases highly likely through around 2025 (see Additional files 7 and 8).

The expected trend of increased use of 2,4-D raises concerns about changes in population exposure, particularly for sensitive populations who may be more vulnerable to harmful effects of exposure. The U.S. EPA provides a "chronic reference dose" (chronic RfD) for certain pesticide chemical exposures. This is defined as "an estimate (with uncertainty spanning perhaps an order of magnitude) of a daily exposure to the human population (including sensitive subgroups) that is likely to be without an appreciable risk of deleterious effects during a lifetime" [27]. For 2,4-D, the chronic RfD based on oral consumption is $0.005 \mathrm{mg} / \mathrm{kg} / \mathrm{day}$ [28]. A biomonitoring equivalent $(\mathrm{BE})$ provides information about how to compare urinary biomonitoring data to the RfD [28]. Toxicokinetic research indicates that the RfD of $0.005 \mathrm{mg} /$ $\mathrm{kg} /$ day of 2,4-D is roughly equivalent to a creatinine adjusted urinary concentration of $300 \mu \mathrm{g} / \mathrm{g}$ in the general population [28]. Prior CDC evaluation of NHANES data indicates urinary concentrations of 2,4-D in the general population continued to be orders of magnitude below the BE of the RfD through 2014 [29]. This is the latest survey in which NHANES includes 2,4-D data, and other biomonitoring studies have confirmed these results [30].

The results of this study deserve careful consideration in the context of herbicide exposure given all that is already known about the human health effects of herbicides from animal and epidemiologic studies. While the carcinogenicity of 2,4-D has been intensively studied and long debated [31, 32], new studies have heightened concern. A 2020 longitudinal biomarker study linked 2,4-D with increased systemic markers of oxidative stress [33]. Association between 2,4-D exposures and nonHodgkin lymphoma (NHL) have been reported, with a recent meta-analysis showing that highly exposed groups experience an elevated relative risk of NHL $(R R=1.73$, CI: 1.10-2.72) [34]. The risk of pediatric leukemia is increased in children residing near areas sprayed heavily with herbicides, including 2,4-D and dicamba [35], 
raising concerns about the impact of exposure to this herbicide on pediatric populations.

Non-cancer outcomes such as birth defects and pediatric anatomical abnormalities have also been linked to 2,4-D. A 1996 study linked licensed pesticide applicators to birth defects from the state birth registry and found an increased rate of birth defects in children of applicators who applied chlorophenoxy herbicides such as 2,4-D [36]. More recently, a case control study assessing birth defects in infants found an association between 2,4-D exposure and hypertrophic pyloric stenosis, patent ductus arteriosus, and hypospadias in male infants [37]. In adults, health outcomes as diverse as allergic wheeze [38], hypothyroidism $[39,40]$ and olfactory deficits [40] have all been linked to 2,4-D exposure.

In this analysis, several vulnerable population subgroups demonstrated an increased odds of higher urinary levels of 2,4-D associated with increased magnitude of 2,4-D use in agriculture. These subgroups include the youngest age group evaluated in NHANES surveys (children aged 6-11), as well as the oldest age group (adults aged 60+). Likewise, women of reproductive age also demonstrated increased odds of high exposure with rising agricultural use of 2,4-D.

Children may be at risk of higher exposure levels due to children's play behaviors that include more time outdoors and on the floor, where there are higher quantities of dirt or dust particles with herbicide residue [41-43]. NHANES did not evaluate children under the age of 6 during the survey cycles included in this study. While the results here indicate a trend toward increasing exposure as age decreases, the data may not generalize to children under age 6 because of differences in types and amounts of food eaten, the ratio between amount of food eaten and unit of body weight, and the amount of accidental herbicide ingestion through play and mouthing behaviors [24]. This gap in knowledge is of critical concern because current knowledge of 2,4-D exposure dynamics [15] suggest that these differences may place younger children at even greater risk for higher exposure than their older counterparts. Further, young children are generally at higher risk for adverse health and developmental outcomes due to physiologic and developmental differences from adults [24]. Biomonitoring studies of 2,4-D exposure in pregnant women and young children are needed because of their unique vulnerabilities to both exposure and adverse health outcomes.

Only a small number of participants classified as agricultural workers were included in this study $(n=139)$. As expected, they were significantly more likely to have higher urinary 2,4-D concentrations compared to participants not classified as agricultural workers. This correlates with previous research on exposure to 2,4-D and other pesticides in agricultural workers $[44,45]$.

Non-Hispanic White participants had increased odds of higher exposure in both unadjusted and adjusted models compared to participants of other races/ethnicities. Because the models controlled for other variables related to socioeconomic status (SES), the differences probably cannot be explained entirely by factors related to SES. Although Non-Hispanic White participants had the highest odds of exposure compared to all other racial/ethnic groups, the difference was greatest between Non-Hispanic White and Non-Hispanic Black participants. It is possible that racial differences in geographic distribution, in particular legacy effects of racism resulting from formal and informal real estate redlining and segregation [46-48] may play a role in the differences in exposure between Black and White survey participants.

Race was included in this analysis recognizing it may serve as a proxy variable for geographic location and proximity to agricultural land and non-agricultural managed greenspace, including residential lawns [49-51]. In 2003, 2,4-D was applied at higher rates to American lawns and greenspaces than any other household herbicide on market [52]. The increase of southern Black migrants into northern cities through the 1960's and 70's drove many White families into suburban areas, where each home was often accompanied by a lawn in the front or back, and sometimes both [53]. Even in cities, urban greenspace is likely to be disproportionately distributed to White residents [54]. While these forms of structural racism often explain higher environmental exposure burdens among Black Americans [55-57], in this case, because non-agricultural uses relate primarily to lawns and green space, they may explain the apparent lower exposure burden among Black and other minority NHANES participants compared to Whites.

There was not a significant difference in biomarker levels by time of year of testing. It is expected that exposures are likely higher during the spray season for some people because of increased inhalation and dermal exposures due to proximity to land in agricultural use. However, NHANES reports testing season data in 6-month intervals that do not directly align with herbicide spraying season, which may explain why differences by time of year of testing were not statistically significant. The lack of control for geographic location in the analysis may have attenuated actual differences, or exposure may occur primarily through sources not dependent on proximity to agricultural land, such as through dietary sources or nearby lawn care applications. 
There are some important limitations of this study, including that it did not evaluate health endpoints. The purpose of this study focused on determining whether changes in agricultural uses of 2,4-D are affecting human exposures. Variable limits of detection of 2,4-D biomarkers across survey cycles and a high percentage of biomarker values below the LOD affect the quantification of population exposure; it was not possible to evaluate associations with the mean population exposure level or its changes over time. Because 2,4-D has an expected half-life in humans of $10.2-28.5 \mathrm{~h}$ and is nearly completely cleared within 3 days [1], one-time spot urine samples provide information on a window of exposure immediately prior to sample collection but reflect neither the expected high variability in exposure levels from individual to individual, nor seasonal changes.

With these recognized limitations, studies tracking associations between agricultural pesticide application and human pesticide exposures are scant. As far as we are aware, this is the first study to evaluate 2,4-D biomonitoring levels and agricultural use of 2,4-D in a large nationally representative survey. In 2020, agricultural use of 2,4-D reached 33.3 million pounds nationally, reflecting a nearly $200 \%$ increase over the 2002 level (see Additional file 1). This rate of growth in the last two decades, however, will likely be dwarfed by the rate of growth and absolute annual increases in total pounds of 2,4-D applied in the next decade. Particularly sharp increases are expected in the next 3-5years on soybean and cotton crop acres as the supply of 2,4-D-tolerant DuoEnlist ${ }^{\mathrm{TM}}$ seeds expands.

2,4-D serves as a sentinel for anticipated changes in other herbicide exposure levels, the application of which are changing in concert with changes in 2,4-D use (see Additional Files 5 and 6). Many of these herbicides have never been included in NHANES or other national biomonitoring studies. Continued monitoring of urinary 2,4-D levels by NHANES is strongly recommended, along with other herbicides that are increasing in use and potentially in exposure (e.g., glufosinate, dicamba, and 4-hydroxyphenylpyruvate dioxygenase (HPPD) inhibitors), as these will be used in progressively higher amounts over the coming years [58-60]. If these application trends unfold as predicted, the analyses reported here signal higher exposures to humans in the near future.

\section{Conclusion}

Given substantial growth in agricultural use of 2,4-D since 2002 and the prospect of more significant growth through around 2030, the reported association between
2,4-D crop application and human biomonitoring levels is worrisome, particularly for vulnerable populations. Because herbicide use is rising, focused biomonitoring and epidemiological evaluation are needed to identify whether and how use and exposures are related to adverse health outcomes among vulnerable populations (particularly children and women of childbearing age) and highly exposed individuals (such as farmers, other herbicide applicators, and their families).

\section{Abbreviations \\ 2,4-D: 2,4-Dichlorophenoxyacetic acid; AHS: Agricultural Health Study; CDC: U.S. Centers for Disease Control and Prevention; EPA: U.S. Environmental Pro- tection Agency; LOD: Limits of Detection; NASS: National Agricultural Statistics Service; NHANES: National Health and Nutrition Examination Survey; PUDS: Pesticide Use Data System; SES: Socioeconomic status; USDA: United States Department of Agriculture.}

\section{Supplementary Information}

The online version contains supplementary material available at https://doi. org/10.1186/s12940-021-00815-x.

Additional file 1. Pounds of 2,4-D Applied on National Acres, 1991-2014. A table of the pounds of 2,4-D applied over time by crop.

Additional file 2. Individual Analytes of 2,4-D as reported in NASS Chemical Use Surveys. A table of individual 2,4-D analytes as reported in NASS Chemical Use Surveys

Additional file 3. Percent National Acres Treated with Glyphosate by Crop Over Time. A table of demonstrating the change in the percent of acres of selected crops treated with glyphosate over time.

Additional file 4. Percent National Acres Treated with Glyphosate. A figure showing the percent national cotton and soybean acres treated with glyphosate over time.

Additional file 5. Percent Soybean National Acres Treated with Top Herbicides Over Time. A figure showing the percent national soybean acres treated with top herbicides over time.

Additional file 6. Percent Corn National Acres Treated with Top Herbicides Over Time. A figure showing the percent national corn acres treated with top herbicides over time.

Additional file 7. Percent Crop Acres Treated with 2,4-D. A figure showing the percent national crop acres treated with 2,4-D over time.

Additional file 8. Pounds of 2,4-D Applied. A figure showing the pounds of 2,4-D applied over time for major crops.

\section{Authors' contributions}

The authors confirm contribution to the paper as follows: study conception and design: MSF, CRR, CMB, HAY, DMH, PDW, and MJP; data collection: CMB and MSF; analysis and interpretation of results: MSF, CRR, CMB, HAY, MJP; draft manuscript preparation and editing: MSF, CRR, CMB, HAY, DMH, PDW, MJP. All authors reviewed the results and approved the final version of the manuscript.

Funding

This research was not funded.

\section{Availability of data and materials}

The datasets generated and/or analyzed during the current study are available in the NHANES repository, https://www.cdc.gov/nchs/nhanes/index.htm, and the Pesticide Use Data System repository, https://hygeia-analytics.com/pesti cides/usage/puds-the-pesticide-use-data-system/. 


\section{Declarations}

Ethics approval and consent to participate

Not Applicable.

\section{Consent for publication}

Not Applicable.

\section{Competing interests}

CMB has served as an expert witness in litigation involving herbicides. MJP has provided expert legal consultation pertaining to COVID and occupational health, and the health effects of chlorpyrifos exposure on children. MSF and CRR received doctoral support funding from the Heartland Health Research Alliance. The other authors declare they have no competing interests.

\section{Author details}

'Department of Environmental and Occupational Health, Milken Institute School of Public Health, The George Washington University, 950 New Hampshire Ave NW Suite 400, Washington, DC 20052, USA. ${ }^{2}$ Heartland Health Research Alliance, Ltd., Brookfield, WI, USA. ${ }^{3}$ Department of Obstetrics and Gynecology, Indiana University School of Medicine, Indianapolis, Indiana, USA. ${ }^{4}$ Neonatology, Indiana University School of Medicine/Riley Hospital, Indianapolis, Indiana, USA.

Received: 26 August 2021 Accepted: 8 December 2021

Published online: 10 February 2022

\section{References}

1. Agency for Toxic Substances and Disease Registry. Toxicological Profile for 2,4-Dichlorophenoxyacetic acid [Internet]. 2020 [cited 2021 Jan 18]. Available from: https://www.atsdr.cdc.gov/ToxProfiles/tp.asp?id=1481\& $\mathrm{tid}=288$

2. Peterson MA, McMaster SA, Riechers DE, Skelton J, Stahlman PW. 2,4-D past, present, and future: a review. Weed Technol. 2016;30(2):303-45.

3. U.S. Environmental Protection Agency. Pesticides Industry Sales and Usage 2008-2012 Market Estimates [Internet]. 2015 [cited 2021 Aug 12]. Available from: https://www.epa.gov/pesticides/pesticides-industrysales-and-usage-2008-2012-market-estimates

4. U.S. Centers for Disease Control and Prevention. Biomonitoring Summaries: 2,4-Dichlorophenoxyacetic Acid [Internet]. National Biomonitoring Program. 2016 [cited 2021 Jan 18]. Available from: https://www.cdc.gov/ biomonitoring/2,4-DichlorophenoxyaceticAcid_BiomonitoringSummary. html

5. Mandel J, Alexander B, Baker B, Acquavella J, Chapman P, Honeycutt R. Biomonitoring for farm families in the farm family exposure study. Scand J Work Environ Health. 2005;31(1):98-104.

6. Alexander BH, Mandel JS, Baker BA, Burns CJ, Bartels MJ, Acquavella JF, et al. Biomonitoring of 2,4-Dichlorophenoxyacetic acid exposure and dose in farm families. Environ Health Perspect. 2007;115(3):370-6.

7. Arbuckle TE, Ritter L. Phenoxyacetic acid herbicide exposure for women on Ontario farms. J Toxicol Environ Health A. 2005;68(15):1359-70.

8. Morgan MK, Sheldon LS, Thomas KW, Egeghy PP, Croghan CW, Jones PA et al. Adult and children's exposure to 2,4-D from multiple sources and pathways. J Expo Sci Environ Epidemiol. 2008;18(5):486-94.

9. Nishioka MG, Lewis RG, Brinkman MC, Burkholder HM, Hines CE, Menkedick JR. Distribution of 2,4-D in air and on surfaces inside residences after lawn applications: comparing exposure estimates from various media for young children. Environ Health Perspect. 2001:109(11):1185-91.

10. Lin B-H, Padgitt M, Bull L, Delvo H, Shank D, Taylor H. Pesticide and Fertilizer Use and Trends in U.S. Agriculture [Internet]. United States Department of Agriculture; 1995 [cited 2021 May 9]. Report No.: 717. Available from: https://naldc.nal.usda.gov/download/CAT10831382/PDF

11. Andrilenas PA. Farmers' Use of Pesticides in 1971 -- Quantities. Agric Econ Rep [Internet]. 1974 [cited 2021 May 9];252. Available from: https://ageco nsearch.umn.edu/record/307500

12. Mirel LB, Burt V, Curtin LR, Zhang C. Different Approaches for NonResponse Adjustments to Statistical Weights in the continuous NHANES
(2003-04). In: Federal Committee on Statistical Methodology Research Conference [Internet]. Washington, DC; 2009 [cited 2020 Jan 18]. Available from: https://nces.ed.gov/FCSM/pdf/2009FCSM_Mirel_V-B.pdf

13. National Center for Health Statistics, Center for Disease Control and Prevention. NHANES 2011-2012: Pesticide Use Data Documentation, Codebook, and Frequencies [Internet]. 2013 [cited 2021 Jan 18]. Available from: https://wwwn.cdc.gov/Nchs/Nhanes/2011-2012/PUQMEC G.htm

14. Baharuddin MRB, Sahid IB. Noor MABMohd, Sulaiman N, Othman F. pesticide risk assessment: a study on inhalation and dermal exposure to 2,4-D and paraquat among Malaysian paddy farmers. J Environ Sci Health Part B. 2011:46(7):600-7.

15. 2,4-Dichlorophenoxyacetic Acid (2,4-D) | Toxicological Profile |ATSDR [Internet]. [cited 2021 Mar 21]. Available from: https://wwwn.cdc.gov/ TSP/ToxProfiles/ToxProfiles.aspx? $\mathrm{id}=1481$ \&tid $=288$

16. U.S. Centers for Disease Control and Prevention. National Health and Nutrition Examination Survey: 2013-2014 Data Documentation, Codebook, and Frequences [Internet]. 2020 [cited 2021 Jul 19]. Available from: https://wwwn.cdc.gov/Nchs/Nhanes/2013-2014/UPHOPM_H.htm\#Descr iption_of_Laboratory_Methodology

17. National Center for Health Statistics, Center for Disease Control and Prevention. National Health and Nutrition Examination Survey 2011-2012 Data Documentation, Codebook, and Frequencies Occupation [Internet]. 2017 [cited 2021 Jan 18]. Available from: https://wwwn.cdc.gov/Nchs/ Nhanes/2011-2012/OCQ G.htm

18. U.S. Centers for Disease Control and Prevention. Vital signs: nonsmokers' exposure to secondhand smoke --- United States, 1999-2008. MMWR Morb Mortal Wkly Rep. 2010;59(35):1141-6.

19. Benbrook CM. Trends in glyphosate herbicide use in the United States and globally. Environ Sci Eur. 2016;28(1):3.

20. Korn EL, Graubard BI. Epidemiologic studies utilizing surveys: accounting for the sampling design. Am J Public Health. $1991 \mathrm{Sep}$ 1:81(9):1166-73.

21. National Center for Health Statistics, Center for Disease Control and Prevention. Analytic and Reporting Guidelines: The National Health and Nutrition Examination Survey [Internet]. 2006 [cited 2021 Jan 18] Available from: https://wwwn.cdc.gov/nchs/data/nhanes/analyticgu idelines/05-06-analytic-guidelines.pdf

22. U.S. Centers for Disease Control and Prevention. National Health and Nutrition Examination Survey Analytic Guidelines, 2011-2014 and 2015-2016 [Internet]. 2018 [cited 2021 Jan 31]. Available from: https:// wwwn.cdc.gov/nchs/data/nhanes/analyticguidelines/11-16-analyticguidelines.pdf

23. Barr DB, Wilder LC, Caudill SP, Gonzalez AJ, Needham LL, Pirkle JL. Urinary Creatinine concentrations in the U.S. population: implications for urinary biologic monitoring measurements. Environ Health Perspect. 2005;113(2):192-200

24. U.S. Environmental Protection Agency. Child-Specific Exposure Factors Handbook [Internet]. 2008 Sep [cited 2021 Jan 18]. Available from: https://cfpub.epa.gov/ncea/risk/recordisplay.cfm?deid=199243

25. Green JM. Current state of herbicides in herbicide-resistant crops. Pest Manag Sci. 2014;70(9):1351-7.

26. Nandula VK. Glyphosate resistance in crops and weeds: history, development, and management. Hoboken, NJ: Wiley; 2010.

27. U.S. Environmental Protection Agency. Reference Dose (RfD): Description and Use in Health Risk Assessments [Internet]. 2014 [cited 2021 Nov 1]. Available from: https://www.epa.gov/iris/reference-dose-rfddescription-and-use-health-risk-assessments

28. Aylward $L L$, Hays SM. Biomonitoring Equivalents (BE) dossier for 2,4-dichlorophenoxyacetic acid (2,4-D) (CAS No. 94-75-7). Regul Toxicol Pharmacol. 2008 Aug 1;51(3, Supplement):S37-48.

29. U.S. Centers for Disease Control and Prevention. National Report on Human Exposure to Environmental Chemicals [Internet]. 2021 [cited 2021 Nov 1]. Available from: https://www.cdc.gov/exposurereport/ index.htm

30. Aylward L, Morgan M, Arbuckle T, Barr D, Burns C, Alexander B, et al. Biomonitoring data for 2,4-dichlorophenoxyacetic acid in the United States and Canada: interpretation in a public health risk assessment context using biomonitoring equivalents. Environ Health Perspect. 2010 Feb $1 ; 118(2): 177-81$. 
31. Goodman JE, Loftus CT, Zu K. 2,4-Dichlorophenoxyacetic acid and nonHodgkin's lymphoma, gastric cancer, and prostate cancer: meta-analyses of the published literature. Ann Epidemiol. 2015 Aug;25(8):626-636.e4.

32. Reuber MD. Carcinogenicity and toxicity of 2,4-dichlorophenoxyacetic acid. Sci Total Environ. 1983 Dec;31(3):203-18.

33. Lerro CC, Andreotti G, Wong JY, Blair A, Rothman N, Freeman LEB. 2,4-D exposure and urinary markers of oxidative DNA damage and lipid peroxidation: a longitudinal study. Occup Environ Med. 2020;77(4):276-80.

34. Smith AM, Smith MT, La Merrill MA, Liaw J, Steinmaus C. 2,4-dichlorophenoxyacetic acid (2,4-D) and risk of non-Hodgkin lymphoma: a meta-analysis accounting for exposure levels. Ann Epidemiol. 2017;27(4):281-9 e4.

35. Malagoli C, Costanzini S, Heck JE, Malavolti M, De Girolamo G, Oleari $P$, et al. Passive exposure to agricultural pesticides and risk of childhood leukemia in an Italian community. Int J Hyg Environ Health. 2016;219(8):742-8.

36. Garry VF, Schreinemachers D, Harkins ME, Griffith J. Pesticide appliers, biocides, and birth defects in rural Minnesota. Environ Health Perspect. 1996;104(4):394-9.

37. Rappazzo KM, Warren JL, Davalos AD, Meyer RE, Sanders AP, Brownstein $N C$, et al. Maternal residential exposure to specific agricultural pesticide active ingredients and birth defects in a 2003-2005 North Carolina birth cohort. Birth Defects Res. 2019;111(6):312-23.

38. Hoppin JA, Umbach DM, Long S, London SJ, Henneberger PK, Blair A, et al. Pesticides are associated with allergic and non-allergic wheeze among male farmers. Environ Health Perspect. 2017;125(4):535-43.

39. Goldner WS, Sandler DP, Yu F, Shostrom V, Hoppin JA, Kamel F, et al. Hypothyroidism and pesticide use among male private pesticide applicators in the agricultural health study. J Occup Environ Med. 2013;55(10):1171-8.

40. Shrestha S, Parks CG, Goldner WS, Kamel F, Umbach DM, Ward MH, et al. Pesticide use and incident hypothyroidism in pesticide applicators in the agricultural health study. Environ Health Perspect. 2018;126(9):97008.

41. Liu J, Schelar E. Pesticide exposure and child neurodevelopment: summary and implications. Workplace Health Saf. 2012;60(5):235-42.

42. Landrigan PJ, Kimmel CA, Correa A, Eskenazi B. Children's health and the environment: public health issues and challenges for risk assessment. Environ Health Perspect. 2004;112(2):257-65.

43. Landrigan PJ, Goldman LR. Protecting children from pesticides and other toxic chemicals. J Expo Sci Environ Epidemiol. 2011;21(2):119-20.

44. Burns CJ, Swaen GMH. Review of 2,4-dichlorophenoxyacetic acid (2,4-D) biomonitoring and epidemiology. Crit Rev Toxicol. 2012;42(9):768-86.

45. Curwin BD, Hein MJ, Sanderson WT, Barr DB, Heederik D, Reynolds SJ, et al. Urinary and hand wipe pesticide levels among farmers and nonfarmers in lowa. J Expo Sci Environ Epidemiol. 2005;15(6):500-8.

46. Probst JC, Moore CG, Glover SH, Samuels ME. Person and place: the compounding effects of race/ethnicity and Rurality on health. Am J Public Health. 2004:94(10):1695-703.

47. Lichter DT, Johnson KM. The changing spatial concentration of America's Rural poor population. Rural Sociol. 2007;72(3):331-58.

48. Cromartie J. Rural America at a Glance [Internet]. 2018 [cited 2021 Jan 21]. Available from: http://www.ers.usda.gov/publications/pub-details/? pubid $=90555$

49. Daniel P. Dispossession: discrimination against African American farmers in the age of civil rights. Chapel Hill, NC: University of North Carolina Press; 2013. 352 p.

50. Horst M, Marion A. Racial, ethnic and gender inequities in farmland ownership and farming in the U.S. Agric Hum Values. 2019;36(1):1-16.

51. Minkoff-Zern L-A, Sloat S. A new era of civil rights? Latino immigrant farmers and exclusion at the United States department of agriculture. Agric Hum Values. 2017;34(3):631-43.

52. Robbins P, Sharp JP. Producing and consuming chemicals: the moral economy of the American Lawn. Econ Geogr. 2003;79(4):425-51.

53. Boustan LP. Was postwar suburbanization "white flight?" evidence from the black migration. Q J Econ. 2010:417-41.

54. Nesbitt L, Meitner MJ, Girling C, Sheppard SRJ, Lu Y. Who has access to urban vegetation? A spatial analysis of distributional green equity in 10 US cities. Landsc Urban Plan. 2019;181:51-79.

55. Bell ML, Ebisu K. Environmental inequality in exposures to airborne particulate matter components in the United States. Environ Health Perspect. 2012;120(12):1699-704.
56. Cassidy-Bushrow AE, Sitarik AR, Havstad S, Park SK, Bielak LF, Austin C, et al. Burden of higher lead exposure in African-Americans starts in utero and persists into childhood. Environ Int. 2017 Nov 1;108:221-7.

57. Perry M, Arrington S, Freisthler MS, Ibe IN, McCray NL, Neumann LM, et al. Pervasive structural racism in environmental epidemiology. Environ Health. In Press.

58. Starkey CE. Use of Hppd-inhibiting herbicides for control of troublesome weeds in the Midsouthern United States. Adv Crop Sci Technol. 2015;04(01):205.

59. Wang H, Liu W, Jin T, Peng X, Zhang L, Wang J. Bipyrazone: a new HPPDinhibiting herbicide in wheat. Sci Rep. 2020;10(1):5521.

60. Moran GR. 4-Hydroxyphenylpyruvate dioxygenase. Arch Biochem Biophys. 2005:433(1):117-28.

\section{Publisher's Note}

Springer Nature remains neutral with regard to jurisdictional claims in published maps and institutional affiliations.
Ready to submit your research? Choose BMC and benefit from:

- fast, convenient online submission

- thorough peer review by experienced researchers in your field

- rapid publication on acceptance

- support for research data, including large and complex data types

- gold Open Access which fosters wider collaboration and increased citations

- maximum visibility for your research: over $100 \mathrm{M}$ website views per year

At BMC, research is always in progress.

Learn more biomedcentral.com/submissions 